\title{
Ação como base para uma estética da subjetividade lúdica
}

\author{
Daniel Vella \\ Doutor; University of Malta, Msida, Malta \\ daniel.m.vella@um.edu.mt \\ Tradução: Samyr Paz \\ Universidade Feevale, Novo Hamburgo, RS, Brasil \\ Universidade Federal do Rio Grande do Sul, Porto Alegre, RS, Brasil \\ samyrpaz@gmail.com \\ Revisão de tradução: Mariana Amaro \\ Universidade Federal do Rio Grande do Sul, Porto Alegre, RS, Brasil \\ mari.amaroc@gmail.com
}

\section{Resumo}

A relevância de reconhecer o senso de agência como sendo fundamental para a experiência da jogadora ao se engajar com o mundo do jogo já foi apresentada com frequência. Neste artigo, eu gostaria de examinar a ideia de que a ação constitui o eu próprio da jogadora, isto é, o senso de quem ela é em relação ao mundo do jogo. Para este fim, a observação concentra-se em jogos nos quais a jogadora se incorpora ao mundo do jogo na forma de uma única figura jogável, estabelecendo uma posiçãosubjetiva lúdica incorporada na qual ela aciona a subjetividade lúdica. O primeiro passo para fundamentar a análise dessa atualização da subjetividade lúdica foca na conceituação da relação entre ação e sujeito. A identificação de um esquema conceitual para atacar esta questão pavimentou o caminho para abordagens da ação por ambas as tradições da filosofia, analítica e continental. Ao seguir esse direcionamento, 0 artigo argumenta que a estrutura experimental do gameplay de jogos digitais se organiza em torno da interação entre a perspectiva interna do mundo do jogo - aquela da posição-subjetiva lúdica e uma perspectiva externa, distanciada, permitindo que a atualização da subjetividade lúdica da jogadora torne-se visível e estruturando uma estética da subjetividade lúdica que é inseparável - e, de fato, consequente à tomada de ações que a jogadora exerce no mundo do jogo.

\section{Palavras-chave}

Ação. Estética. Subjetividade Lúdica. Thief: The Dark Project. 


\section{Introdução}

Pode parecer óbvio constatar que a jogadora de um jogo existe, em relação ao jogo, enquanto um ser ativo. Assim sendo, conforme denominei a "subjetividade lúdica" - "a subjetividade 'eu-no-mundo-do-jogo' - cristaliza a jogadora através do engajamento com o mundo do jogo" (VELLA, 2015, p. 22). Dessa maneira, a jogadora é fundamentalmente um sujeito ativo e a ação é o modo de engajamento com o mundo do jogo.

O que gostaria de abordar neste artigo, entretanto, vai além do reconhecimento do senso de agência como algo fundamental para a experiência de jogadores que se engajam com o mundo do jogo. Isto já foi apresentado com frequência (veja, por exemplo, MURRAY, 1997; MATEAS; STERN, 2005; WARDRIP-FRUIN et al., 2009). Ao invés disso, gostaria de examinar a ideia de que a ação constitui o eu próprio da jogadora dentro do jogo - o senso de quem ela é em relação ao mundo do jogo.

Para ser mais específico, devo limitar minhas observações a jogos que desenvolvem posições-subjetivas lúdicas incorporadas singularmente, conforme definição própria (VELLA, 2016, p. 5). Em outras palavras, jogos nos quais a jogadora é incorporada no mundo do jogo na forma de uma única figura jogável. Considerando essa categoria de jogos, Rune Klevjert se apoia no argumento de Maurice Merleau-Ponty de que a "consciência não é, em primeiro lugar, uma questão de ‘Eu penso', mas sim de 'Eu posso'” (2002 [1945], p. 159) observação que destaca a centralidade da ação, ou a capacidade para ação, na fenomenologia corporificada de Merleau-Ponty - para argumentar que as affordances garantidas pela figura jogável, em relação ao mundo do jogo, representam uma forma “diferente de eu posso" (2012, p. 22), uma articulação diferente da capacidade de agir e, por consequência, de uma consciência diferente.

De maneira semelhante, Marta Matylda Kania argumenta que aquilo que ela chama de a "situação de gameplay" - a subjetividade direcionada ao mundo do jogo, como uma "posição de percepção do self-avatar direcionada ao mundo do jogo" (2017, p. 61) é também algo intrinsicamente conectado à ação. Assim, a situação de gameplay "estabelece condições de experiência que fornecem à jogadora um entendimento pré-concebido das ações que precisam ser desempenhadas para que o jogo seja jogado" (2017, p. 61).

0 modelo de posição-subjetiva lúdica é uma tentativa de formalizar a ideia de "um ponto de vista perceptivo que a figura jogável estabelece para a jogadora em relação ao mundo do jogo" (VELLA, 2015, p. 22). Entende-se isso como uma Gestalt experimental 
definida pela inter-relação do conjunto de mecanismos formais - sendo que um dos mecanismos básicos é o conjunto de capacidades de ações que é concedido a jogadora em relação ao mundo do jogo, e, em associação, as limitações da variedade de ações acessíveis à jogadora no mundo do jogo: os 'Eu posso' e 'Eu não posso'.

Neste artigo, eu considerarei a atualização ${ }^{1}$ da subjetividade lúdica, ou seja, o que acontece a partir de uma perspectiva subjetiva da experiência no mundo do jogo, quando a jogadora inicia o engajamento com o mundo do jogo através da posição-subjetiva lúdica. Dado que esta posição representa a localização perceptiva da jogadora em relação ao mundo do jogo - um ponto de vista experimental e existencial que determina um modo particular de estar-no-mundo-do-jogo - esse engajamento com o mundo do jogo pode então ser compreendido literalmente como a atualização da subjetividade lúdica. Ou seja, colocar-emação concreto.

Para fundamentar a análise da subjetividade lúdica na atualização, começo focando em conceitos da relação entre ação e sujeito. Ao identificar um esquema conceitual para resolver essa questão, eu irei trazer abordagens de ação tanto da tradição da filosofia analítica, em particular de G.E.M. Anscombe, Georg Henrik von Wright e Donald Davidson, como também da filosofia continental, especificamente de Hannah Arendt e Paul Ricoeur.

Partindo da noção de intenção como sendo central para a ação, farei uma pausa na noção de dupla-face da ação e seu entrelaçamento de dimensões internas e externas, antes de considerar a aplicação de Paul Ricoeur da noção de 'Eu posso' de Merleau-Ponty, como meio de associar esses dois aspectos da ação. Seguindo para a ideia de adscrição de intenção, apresentarei de quais maneiras a ação tem sido entendida como um mecanismo de auto revelação por parte do agente nos trabalhos de Arendt e Ricoeur.

Após estas etapas, o debate retornará para o domínio da subjetividade lúdica, através de uma aplicação desta conceituação de ação para a análise de uma situação de jogo em Thief: The Dark Project (Looking Glass Studios, 1998). Será demonstrado, neste estudo de caso, as maneiras pelas quais a subjetividade lúdica é acionada pelo engajamento ativo da jogadora com o mundo do jogo.

Baseado nisso, no movimento final dessa argumentação, vou defender que a estrutura experiencial do gameplay digital, organizada na interação entre uma perspectiva interna do mundo do jogo - aquela da posição-subjetiva - e uma perspectiva externa, distanciada,

\footnotetext{
${ }^{1}$ Nota do tradutor: Daniel Vella utiliza no texto original o termo enactment que, segundo o autor, abrange tanto o sentido de colocar em ação, como tornar concreto. Por não haver termo semelhante em português, Vella sugeriu a utilização de atualização, pois chega próximo ao sentido original.
} 
permite tornar visível a atualização de uma subjetividade lúdica da própria jogadora. Desta forma, estrutura-se uma estética da subjetividade lúdica que é inseparável e, de fato, consequência da tomada de ações da jogadora no mundo do jogo.

\section{Ação e intenção}

Na tradição da filosofia analítica é fundamental a distinção entre ação e um evento em um sentido geral, uma diferenciação que, até certo ponto, é realizada a partir da ideia de que o primeiro é o resultado de uma intenção e o último é resultado de uma causa. De modo mais simples, a diferença é que a intenção se direciona para o futuro, em contraste ao olhar retrospectivo inerente de determinar a causa de um evento. Conforme Georg Henrik von Wright, "causalidade é [...] contrastada com a teleologia, e explicações causais com explicações teleológicas" (1971, p. 83).

Portanto, é com a noção de intenção que a conceituação da ação precisa iniciar. 'Intenção', escreve G. E. M. Ascombe, é em si um termo problemático que pode ser utilizado em, ao menos, três maneiras distintas:

Quando um homem diz 'vou fazer isso e aquilo', devemos dizer que esta é uma expressão de intenção. Também devemos falar que ação é intencional, além de questionar qual intenção a coisa fez. (1979 [1957], p. 1)

Intenção, sendo assim, pode ser compreendida sob a abrangência da "expressão de intenção futura", "ação intencional" - isto é, determinar se uma ação particular foi ou não realizada intencionalmente, e "intenção na ação" (ASCOMBE, 1979). Através desta última noção que esta investigação adotará o conceito de ação.

Nessa proposição, declarar a intenção subjacente a uma ação torna-se um meio de descrever uma ação:

Caso um agente realize $\mathrm{A}$, com a intenção de fazer B, há uma descrição de $\mathrm{A}$ que revela a sensatez na ação, ao iluminar a razão pela qual o agente a desempenhou. (DAVIDSON, 1980, p. 85)

Em resumo, conforme Paul Ricoeur afirma, "dizer o que é uma ação, é dizer por quê ela foi realizada" (1992, p. 63). Isso ainda abre espaço para definir mais rigorosamente a maneira que "intenção" deve ser entendida como explicação da ação. De forma que, intenção é, em primeiro lugar, um fenômeno mental. Anscombe escreve que: 
[...] se queremos saber as intenções de um homem, é no conteúdo da sua mente, e somente neste que devemos averiguar; por consequência [...] se desejamos entender o que é intenção, precisamos investigar algo que existe puramente na esfera da mente. (1979 [1956], p. 9)

Pensar a ação em termos de intenções é alterar o plano no qual a análise da ação é conduzida a partir do domínio ôntico, no qual a ação ocorre na forma de um evento resultando em alguma mudança no estado do mundo - para o plano da consciência, dentro da qual a intenção ocorre. Conforme Ricoeur sugere, intenção deve ser entendida como "o objetivo da consciência em direção a algo que quero fazer" (1992, p. 67). Através desse entendimento, "ação formata a intenção" (Davidson, 1980, p. 89), independente da realização objetiva de alterações no mundo.

\section{Os dois lados da ação}

Isto provoca dificuldades conceituais, ou seja, como dar conta do ponto de encontro entre a origem subjetiva da intenção e o status objetivo da ação em um evento no mundo? Von Wright conceitua isso ao dizer que a ação "apresenta dois aspectos: um "interno" e outro "externo"”, sendo o primeiro "a intencionalidade da ação, a intenção ou a vontade "atrás" das manifestações externas," e o segundo "algum evento" no mundo, como "o fato de que certa manivela gira ou uma janela abre" (WRIGHT; 1971, p. 86-87).

A abordagem de Von Wright de juntar estes dois aspectos da ação é para conecta-los pelo meio de um sistema lógico. Através do seu argumento, uma ação tem significado, pois para o agente, dentro de um contexto de "sistema fechado" (ibid., p.78) no qual o agente está isolado do ambiente, entregue a forma de "condição-espacial" (ibid, p. 49) de tal modo que uma ação intencional pode ser entendida como "interferência" (ibid, p. 61) com a operação autônoma do sistema, a intenção de modificar a organização do sistema de um estado inicial A para o estado final C, que diferencia-se do estado B que o sistema teria alcançado caso fosse deixado para seus próprios dispositivos. Ricoeur explica:

[...] é ao fazer algo que um agente aprende a 'isolar' um sistema fechado do seu ambiente e descobrir as possibilidades no desenvolvimento inerente do sistema. 0 agente aprende isto ao colocar o sistema em movimento, começando por uma condição inicial que o agente 'isolou'. É nesta configuração de coisas em movimento que se constitui a interferência, na intersecção entre uma das habilidades do agente e os recursos do sistema. (RICOUER, 1984, p. 135) 
Tal conceitualização de ação ressoa com inúmeros insights realizados em ambos os domínios da filosofia do jogar e game studies. A noção de isolamento do domínio da ação lúdica foi apontada tanto por Johan Huizinga, na frequente citada descrição da separação do jogar com os próprios "limites característicos do espaço e do tempo" (2000), quanto no desenvolvimento de Eugen Fink sobre a noção de play-world ${ }^{2}$ (2012 [1957]). Além disso, a ideia de jogo como um sistema, desenvolvido no trabalho de Katie Salen e Eric Zimmerman (2004, p. 50), já se tornou comum. Com isso em mente, é oportuno notar que tal entendimento sistêmico está desenhado em direção a experiência no mundo do jogo, conforme a "espiral de gameplay" de engajamento heurístico de Dominic Arsenault e Bernard Perron (2009, p. 115-117), enquadrando-se nos argumentos de von Wright a respeito da maneira que agentes constituem a situação de seus entornos na ordem de um sistema fechado através de experimentação e observação (1971, p. 63-64). Ainda mais especificamente, o argumento de von Wright de que ao ser entendido como uma condiçãoespaço, o sistema pode se tornar um caminho para ação, tem afinidade próxima da caracterização de Jesper Juul de games como "máquinas de condição", com o input da jogadora efetivando um ramo da "árvore do jogo", a ramificação, organizadahierarquicamente na rede de possibilidades de estados de jogo (2005, p. 60).

As congruências entre esta abordagem sistêmica da ação e da abordagem igualmente sistêmica aos jogos são, portanto, claras. Entretanto, apesar do conceito de ação de von Wright nos fornecer explicações para a formação da intenção do sujeito em relação ao entendimento subjetivo de um domínio objetivo como um sistema fechado, ainda não responde a questão central que permeia este entendimento de dupla-face da ação: especificamente, como determinamos o ponto de articulação entre o sujeito intencionado e o mundo objetivo, no qual a intenção é direcionada, dentro do qual se manifesta como um evento físico?

Ricoeur argumenta que a chave para essa "intersecção" está no discurso de MerleauPonty sobre "Eu posso". Neste contexto, o discurso oferece:

[...] uma ontologia do corpo próprio, ou seja, de um corpo que também é o meu corpo, no qual por uma dupla submissão à ordem dos corpos físicos e àquele das pessoas, que assim encontra-se o ponto de articulação do poder

\footnotetext{
${ }^{2}$ Nota do tradutor: por se tratar de um conceito de Eugen Fink, preferiu-se não traduzir o termo. Daniel Vella explanou via email que a ideia de play-world desenvolvida por Fink refere-se ao mundo criado por meio do jogar, uma espécie de esfera de aparências super imposta ao mundo real. Fink oferece o exemplo de play-world a partir de uma criança que brinca com uma boneca e imagina um mundo onde ela é uma mãe e o brinquedo uma filha.
} 
de agir que é nosso e no curso das coisas que pertencem a ordem do mundo. (Ricoeur 1992, p. 111).

A observação de Ricoeur diz que, segundo Merleau-Ponty, essa natureza dupla é a característica essencial do corpo. Conforme Merleau-Ponty:

[...] nosso corpo é um ser de duas folhas, de um lado uma coisa entre coisas e, do outro, o que as vê e as toca [...] ele [o corpo] une essas duas propriedades dentro de si mesmo, e este duplo pertencimento à ordem do "objeto" e à ordem do "subjetivo" revela para nós relações bastante inesperadas entre essas duas ordens. (1968, p. 137).

Merleau-Ponty ilustra essa dupla-face do corpo ao meditar sobre a mão tanto como um instrumento de toque e como sendo ela mesma aberta, pelo toque da outra mão, para encontrar-se como uma coisa-no-mundo: "em um autêntico tocar do toque, quando minha mão direita toca minha mão esquerda [...] o "sujeito tocando" passa para classificação do tocado" (ibid, p. 134). Em resumo, é pela nossa natureza de dupla-face de seres corporificados, de ambas subjetividades conscientes e de corpo no mundo, que o "Eu posso" é tanto uma estrutura da nossa experiência subjetiva do mundo, quanto uma capacidade de agir no domínio ontológico das coisas no mundo do qual nós pertencemos como corpo.

A respeito da subjetividade lúdica, esta dupla-face do corpo é refletida na relação fenomenológica de dupla-face da jogadora e sua figura jogável, pelo qual a figura é tanto um ponto de vista subjetivo para a jogadora em relação ao mundo de jogo, quanto uma entidade objetiva, de pertencimento ontológico no mundo do jogo (Vella, 2015, p. 228). É graças a esta dupla-face que as intenções da jogadora em agir podem tomar forma externa e material de uma mudança no estado do mundo do jogo.

\section{Ação como auto revelação}

Há um ponto final que eu gostaria de extrair de uma consideração sobre a noção de intenção: que ela requer adscrição a um agente. Conforme Ricoeur argumenta, "por intenção nós dizemos que é a intenção de alguém, e por este alguém nós dizemos que ele ou ela pretende fazer algo" (1992, p. 95). O uso do termo 'adscrição' por Ricoeur destaca não apenas a prerrogativa da intenção do agente (no sentido de dizer "que esta intenção A pertence ao agente $\left.\mathrm{B}^{\prime \prime}\right)$, porém, mais radicalmente, à sua pertença ao agente na veia da 
pressuposição sobre quem o agente é: "adscrição marca a referência de todos os termos no ponto fundamental da rede conceitual ao seu ponto crucial: "quem?"” (ibid.). Ao atribuir uma intenção a um indivíduo, estamos falando algo sobre o indivíduo, através da definição de predicado mental (Strawson, 1959, p. 104): nós adicionamos, ao conjunto de predicados pelos quais nós conhecemos o indivíduo, o conhecimento de que esse é alguém que tem essa intenção. Em outras palavras, nós conhecemos o indivíduo através de suas intenções, nas quais, da mesma maneira, apenas podemos conhecer suas intenções baseadas em um ato interpretativo de adscrição.

Claro que as próprias ações de alguém não demandam intepretação da mesma forma, dado que elas pertencem a categoria de coisas que este alguém "conhece sem observação" (ibid., p. 13), precisamente devido à posse proprioceptiva ${ }^{3}$ destas ações. Conforme Ricoeur:

Eu não digo que eu sei que fazia isto ou aquilo porque eu havia observado. É em fazer que alguém sabe que esse alguém está fazendo algo, o que este alguém está fazendo e o porquê alguém está fazendo. (1992, p. 70)

Ou, nas palavras de Max Scheler, "é essencial para o Ser das ações que elas sejam Experimentadas apenas em suas próprias performances" (1973 [1916, p. 371). Isto, claro, é o resultado da mesmidade fundamental da subjetividade intencional em primeira-pessoa. Sendo assim, qual o papel que a adscrição da intenção tem na análise do eu-mesmo na ação?

Para Hannah Arendt, ação distingue-se tanto de tarefas e do trabalho. A base para essa distinção - o que faz uma ação ser ação - é que, ao contrário de "mera atividade produtiva", ação conta com a "tendência inerente de revelar o agente junto com a ação" (1998 [1958], p. 180). Ação, portanto, representa uma auto revelação por parte do ator - independente do que seja, ação sempre constitui em uma resposta para a pergunta "Quem é você?" (ibid., p. 178).

Esta auto revelação não deve ser entendida como consciente ou desejada, mas como uma revelação involuntária ou inevitável do caráter essencial de alguém perante a comunidade - "alguém revela a si mesmo sem nunca saber ele mesmo ou ser capaz de calcular previamente quem ele revela" (ibid., p. 192).

Ricoeur segue Arendt ao destacar esta característica de revelação da ação, porém diverge do trabalho da autora neste último ponto. Dada a situação de deliberação antes das oportunidades para ação, por meio da posição existencial de alguém, Ricoeur argumenta

\footnotetext{
3 Nota do tradutor: conforme definição do dicionário Michaelis 2018 proprioceptiva define-se como "a capacidade de reconhecer a localização espacial do corpo" (PROPRIOCEPTIVA, 2018).
} 
que "decidir-se é definir o debate tornando sua uma das opções consideradas" (RICOEUR, 2014, p. 88). A livre decisão de agir - ser deparado com a diversidade múltipla de possíveis ações, escolher uma e fazer dela minha - vem a ser entendida como uma auto-adscrição. 0 desempenho de uma ação intencional - o direcionamento de mim mesmo, como ser-nomundo, na direção de uma mudança que eu quero trazer ao mundo - é, ao mesmo tempo, determinação consciente de quem eu sou. Através da tomada de ação no mundo, portanto, 'Eu' venho a constituir-me como 'Eu, definido por um conjunto de ações que eu mesmo atribuo a mim ao performá-las.

\section{A subjetividade lúdica em ação}

Contra o plano de fundo desta conceituação da ação e sua relação do sujeito enquanto agente, é possível debater a questão da ação relacionada à subjetividade lúdica, e como ela auxilia na constituição do eu lúdico.

Antes da tomada de ação propriamente dita, é pela disposição em direção a ação que a jogadora-enquanto-sujeito-lúdico-de-ser-no-mundo orienta-se perante sua situação - ponto que Gordon Callega destaca ao argumentar que a relação da jogadora com o mundo do jogo é "em primeiro lugar e antes de tudo uma disposição em estar pronto para agir" (2011, p. 41).

Um exemplo pode ajudar a ilustrar este ponto. Durante o jogo Thief: The Dark Project (Looking Glass, 1998), a jogadora, atuando como o ladrão mestre Garret, encontra-se nos andares superiores de uma mansão palaciana. Escondida em um recanto escuro, a jogadora consegue visualizar o corredor que deve ser atravessado, para chegar até a sala que contém um item que precisa ser roubado. Duas tochas iluminam o corredor, e um par de guardas vigiam o fim deste corredor. Oculta no escuro, a jogadora-como-Garret está segura. De outro modo, Garret certamente seria visto, caso a jogadora deixasse a segurança da escuridão.

Aqui, a jogadora pode permanecer imóvel por vários minutos, sem tomar ação alguma e, ainda assim, por todo o tempo ela poderia, em um nível subjetivo, estar longe de inativa. A jogadora pode medir a situação, observando o movimento dos guardas e tentar calcular a frequência do padrão das rondas. Ela poderia consultar o mapa e tentar determinar onde ela seria capaz de evitar os guardas, ao tomar uma rota indireta. Ela poderia procurar no inventário por algum item que pudesse ser usado para causar uma distração, conduzindo os guardas para fora de seus postos. Em todas essas possibilidades, apesar da jogadora não 
desempenhar ação alguma, alguém estaria enganado ao afirmar que ser-no-mundo-de-jogo da jogadora não é marcado por uma disposição ativa intensa, e que isso não é intimamente ligado a incorporação dela no mundo do jogo como Garret.

Em resumo, a jogadora, baseada no "Eu posso" que ela "é" como um sujeito lúdico incorporado, está considerando a rede de possibilidades de ação constituindo a complexidade instrumental em que, conforme os termos existenciais de Sartre, também são, como possibilidades dela, parte do ser dela. É nestes termos fenomenológicos que uma situação é estabelecida contra qual agência pode ser exercida, na forma do "poder satisfatório de tomar ações significativas", para retornar à formulação de Janet Murray (1997, p. 126).

Nesta situação a jogadora pode decidir, após deliberar, em usar seu estoque limitado de flechas de água para apagar as tochas do corredor, permitindo que ela-mesma-enquantoGarret prossiga sem ser vista. Seguindo a teoria da ação de von Wright, compreende-se isso da seguinte maneira: a jogadora percebe que o sistema que constitui o mundo do jogo encontra-se em um estado A (o corredor está iluminado), e forma uma intenção para agir de uma forma que resulta no estado B (o corredor apaga-se). Ela poderia facilmente ter decidido em favor de outras possibilidades que formam seu complexo instrumental como, por exemplo, usar flechas normais para matar os dois guardas - desse modo, nos termos de von Wright, atuando em diferentes ramos do espaço de possibilidades de estados-domundo, resultando em um novo estado C (no qual o corredor continua iluminado, porém os guardas estão mortos).

Pode ser que, sem dúvidas, o resultado da ação da jogadora não combine com suas intenções: o estado de jogo resultante, neste caso, seria diferente do que ela previu. A ação poderia falhar: a jogadora, por exemplo, poderia julgar mal o anglo no qual ela lançaria suas flechas de água e, como resultado, errar as chamas das tochas completamente, levando a um estado de mundo D (o corredor continua aceso e os guardas vivos, porém Garret tem duas flechas de água a menos no seu inventário). Alternativamente, a ação poderia ser um sucesso, acarretando no estado B conforme era a intenção original da jogadora, porém poderia colocar em movimento uma corrente de causas e efeitos não previstas pela jogadora. Talvez a jogadora consiga apagar as tochas com flechas de água, porém isso alertaria os guardas de que algo está errado, causando que eles saiam do seu padrão de rondas e movam-se próximo à posição de Garret. Isto irá resultar em um novo estado-domundo e, por consequência, em uma nova situação na qual a jogadora-como-Garret, baseada 
no mesmo 'Eu posso' e na maneira que a situação é resolvida em um complexo instrumental de possibilidades, deve formar uma nova intenção e assim por diante.

Apesar deste elemento de imprevisibilidade que caracteriza qualquer tradução de intenção em ação, o que se revela aqui é uma essencial orientação-ao-futuro ou uma característica teleológica da subjetividade lúdica - ao menos até que se relacione e seja constituída pela sua capacidade para ação. A ação de lançar flechas de água nas tochas, portanto, tem a intenção de levar a um estado-de-mundo-de-jogo desejado. Além disso, a ação do individuo, e a intenção por trás dessa, conecta-se na corrente-de-ações que seguem a orientação-aos-objetivos globais do sujeito lúdico. A respeito disso, Pedtri Lakoski fala sobre a intenção atribuída a cada ação individual dentro do jogo como se fundindo numa dimensão granular de "sub-objetivos" de momento-para-momento, orientados em direção a realização dos “ objetivos regulatórios” (2011, p. 297) abrangentes - o qual, em termo da constituição do sujeito lúdico, representam os projetos existenciais para os quais seu ser-nomundo é direcionado.

\section{A auto revelação do sujeito lúdico}

Conforme o texto acima, não há dúvidas que a jogadora atribui a si-mesma a ação tomada, e não a Garret como personagem separado dela própria. É ela quem detém a consciência interna para deliberar, de perceber as possibilidades como as possibilidades dela. Finalmente, é ela quem atribui a si-mesma a intenção de lançar as flechas de água e, ao mesmo tempo, de decidir não matar os guardas.

Agindo dessa maneira, seguindo o argumento de Ricoeur sobre a auto- adscrição da ação, a jogadora não está apenas escolhendo uma, entre tantas possibilidades de estados-domundo que podem resultar da variedade de "Eu posso" disponíveis a ela. Ao mesmo tempo, ela também determina a própria subjetividade lúdica através de sua atualização: tão logo que a ação é tomada, ela se torna parte de um conjunto de ações que ela reconhece como dela mesma.

A respeito da ação particular que usei neste exemplo, a decisão de apagar as tochas ao invés de, digamos, correr o risco de atravessar o corredor iluminado, sugere uma disposição cuidadosa e meticulosa; ao mesmo tempo, a decisão de evitar matar os guardar pode revelar uma decisão ética de matar apenas quando absolutamente necessário, mesmo que, neste caso, matar os guardas eliminaria o risco de ser apanhada. Este princípio moral, portanto, 
está atribuído ao sujeito lúdico da 'jogadora-como-Garret', a qual, conforme a subjetividade lúdica dela, a jogadora relaciona-se proprioceptivamente. Dessa maneira, a tomada de ação é inseparável da adscrição das qualidades "Eu sou alguém meticuloso" e "Eu sou alguém que evita matar" a este sujeito lúdico.

Aqui o sentido da frase "atualização da subjetividade lúdica" se torna claro, pois é apenas por meio do engajamento da jogadora com o mundo do jogo, através do enquadramento do posicionamento-do-sujeito lúdico, que o sujeito lúdico se torna determinado, não apenas como 'história de vida', mas também, conforme o exemplo acima, como conjunto de predicados definidos que podem ser extraídos de tal 'história de vida'.

Ainda é necessário explicar que, ao jogar Thief, a jogadora está consciente que a figura que ela controla é o titular ladrão, um homem chamado Garret, que vive em uma cidade medieval steampunk, ambiente que constitui a representação do mundo ficcional do jogo. 0 game fornece à jogadora uma matriz que Uri Margolim identifica como "declarações de caracterização" (1986, p. 206), permitindo a ela construir uma ideia coerente de quem Garret é enquanto pessoa, definida através de conjuntos de predicados que, muito provavelmente, não contém muitas sobreposições com o conjunto de predicados na qual a jogadora definiria a si mesma como pessoa. Entre a história dele, sua voz, aparência física, e ações na qual os eventos o levam a desempenhar, a jogadora constrói um entendimento de Garret como alguém meticuloso, paciente, habilidoso, de raciocínio rápido, corajoso, porém cauteloso, longe de ser imprudente, com camadas de cinismo sarcástico e uma nítida - mas não completa - amoralidade.

Estas características são de Garret, não da jogadora - mas para jogar Thief, toma-se uma posição de subjetividade delineada por estes atributos como se fossem seus. Certamente, em algum grau de intepretação de papeis - a vontade consciente ou inconsciente de "habitar a mente de outro alguém" (Bowman, 2010, p. 8) - pode ser um fator a ser considerado. Fundamentalmente, entretanto, é o mecanismo de posicionamentodo-sujeito lúdico que leva a jogadora a "ver como" e "jogar como" Garret. É a vulnerabilidade física deste personagem que necessita cautela, pois é impossível sobreviver a uma luta direta com muitos agressores. Isso demanda raciocínio rápido, caso um plano saia errado e Garret seja visto, a necessidade de esperar e observar a rota de patrulha dos guardas de um ponto de vista vantajoso e oculto que requer paciência, a multiplicidade de possíveis abordagens e caminhos transversais que demanda astúcia em escolher a melhor opção em uma dada situação e, assim por diante. Desta maneira, a jogadora não apenas decide 
conscientemente como ela irá 'jogar como' Garret, mas o ser-no-mundo-do-jogo que Thief estabelece leva a jogadora a adotar a subjetividade de Garret como dela própria, pensando nela mesma como Garret.

\section{Subjetividade lúdica como uma estética da ação}

Para Arendt e Ricoeur, a importância da ação está dissociada do seu resultado material final. Esta é uma abordagem à ação que "salienta a necessidade da auto revelação aos custos de todos os outros fatores" (Arendt, 1998 [1958], p. 194). Arendt parte de Aristóteles (Ética à Nicômaco, 1094a, p. 1-5) para caracterizar a ação como energeia, na qual “o fim (telos) não é perseguido, porém se encontra na própria atividade" (Arendt, 1998, p. 206). Apesar da ação ser invariavelmente uma intenção orientada em direção de realizar alguma modificação na situação do mundo, a sua auto revelação, ou auto determinação, encontra-se no própria desempenho, independente de atingir o seu fim.

Desnecessário dizer que estes argumentos se aproximam notavelmente dos entendimentos de jogar que já foram trazidos na filosofia. Hans-Gerog Gadamer, em particular, aborda o jogar como "auto representação vívida" do auto-movimento dos seres vivos (1986, p. 23). Para esta auto representação ocorrer, entretanto, a jogadora não pode permanecer firme e exclusivamente ligada à posição-do-sujeito lúdico. Ao invés disso, a sua própria subjetividade lúdica precisa estar disponível a ela como um objeto da percepção - o qual só pode ser o caso se ela for capaz de adotar uma segunda perspectiva, uma perspectiva distanciada pelo enquadramento da percepção de sua própria subjetividade lúdica.

Novamente, a filosofia do jogar antecipou essa ideia. Eugen Fink trata da "existência dupla" da jogadora em "duas dimensões" (2015 [1958], p. 24-25), a qual permite que, a qualquer momento, ela saia da sua atuação de jogo e fique consciente disso como a atuação dela mesma. De maneira semelhante, Gadamer descreve que "no ato de jogar eu estou acima de mim mesmo como espectador" (1986, p. 23).

Não é surpreendente que no domínio da arte interativa, Katja Kwastek argumenta, a partir da noção de jogar, que é por meio da ação que se constitui o "material" do trabalho da arte interativa - no qual o recipiente do trabalho precisa responder ao trabalho "proposto pela interação" precisamente ao tomar ação (2013, p. 47) - "é necessário colocar para fora e experienciar ao mesmo tempo", significando que tais trabalhos artísticos colocam em movimento uma oscilação "entre absorver-se na interação e (auto) refletir à distância" (p. 
162). É graças a essa constante interação entre o ponto de vista do engajamento absorvido e o da reflexão crítica distanciada que "as próprias ações de alguém se tornam disponíveis como um objeto de reflexão." (p. 163).

Enquanto artefatos digitais que configuram propostas interativas no formato do posicionamento-do-sujeito lúdico, jogos digitais seguem uma estrutura experimental similar, na qual abordei em outro trabalho:

[...] a experiência da jogadora com o jogo é determinada pela habitação simultânea dela com dois pontos de vistas fenomenológicos distintos: uma perspectiva interna do mundo do jogo, no qual as ações lúdicas são tomadas a partir de uma orientação teleológica dirigida pelo jogo, e uma perspectiva externa ao jogo e das ações da jogadora, visualizada no modo estético definido pela distância crítica e desinteressada de uma atitude contemplativa (VELLA, 2016, p. 81)

Kania complica ainda mais essas ideias, argumentando que a estrutura dessa perspectiva não é apenas dupla, mas tripla. Segundo seu entendimento, a perspectiva interna se estrutura em torno da ação recíproca entre duas situações subjetivas. Conforme mencionei na introdução deste artigo, a primeira - situação do gameplay - é análoga à ideia de posicionamento-do-sujeito lúdico, sendo que a segunda - situação estética - "reflete-se no curso da posição do $e u$-avatar dentro do game, no qual compreende sua situação enquanto percebe o mundo do jogo" (ibid., p. 69). Mesmo que o termo 'estética' seja um tanto problemático aqui, a ideia do ponto de vista reflexivo sobre a própria posição da jogadora dentro do game é necessária. Para esta situação podemos atribuir, por exemplo, a hesitação da jogadora quando os guardas percorrem sua visão em Thief, enquanto ela considera quem ela é ou quer ser no jogo, e qual curso de ação é o mais concorrente com seu eu-mesmo.

Até agora, isto é precisamente a mesma relação que temos com as ações que desempenhamos em qualquer outro domínio da nossa vida. Nós agimos, pré-reflexivamente, baseados em 'Eu posso' dentro de nossa situação existencial, e somos capazes de tomar um passo atrás reflexivo para contemplar nossas ações e a auto revelação delas. 0 que faz a situação de jogo digital ser diferente está na perspectiva interna, com estes dois pontos de vista subjetivos inter-relacionados, contidos no enquadramento da perspectiva externa, no qual o game é visto de fora como artefato tecnológico (ibid., p. 52). A subjetividade da jogadora dentro do game - tanto as ações intencionais que ela toma no mundo de jogo do ponto de vista da situação de gameplay (ou, para usar o termo que empreguei durante esta 
análise, o posicionamento-do-sujeito lúdico), e seu reconhecimento reflexivo de sua própria subjetividade lúdica pelo qual ela realiza adscrição dessas ações ao eu-mesmo dentro do game - tornam-se assim os elementos da unidade estética do game como objeto.

\section{Conclusão}

É neste sentido, portanto, que as condições estabelecidas pela experiência de jogo digital permitem a possibilidade de uma estética da subjetividade, fundamentada por meio da ação. Através da ação no mundo do jogo da perspectiva do posicionamento-subjetivo lúdico, a jogadora processa um eu-mesmo lúdico - um eu-mesmo que é revelado por meio da própria- adscrição da ação que ela toma no mundo do jogo, emergindo como 'quem' que une todas as ações da jogadora. Este eu-mesmo emerge da reflexão da jogadora sobre suas próprias ações no jogo - mas o que é único na estrutura experiencial dos jogos digitais é a maneira pela qual essa atualização de si-mesmo é ela própria enquadrada dentro da estrutura estética do objeto do jogo.

\section{Referências}

ANSCOMBE, G. E. M. Intention. London: Basil Blackwell, 1979.

ARENDT, H. The Human Condition. Chicago: Chicago University Press, 1998.

ARSENAULT, D.; PERRON, B. "In the Frame of the Magic Cycle". In: The Video Game Theory Reader 2. PERRON, B.; WOLF, M.J.P. (eds.). New York: Routledge, 2009. pp. 109-132.

BOWMAN, S.L. The Functions of Role-Playing Games. Jefferson, NC: McFarland. 2010.

CALLEJA, G. In-Game: From Immersion to Incorporation. Cambridge, MA: MIT Press. 2011.

DAVIDSON, D. Intending. In: DAVIDSON, D. Essays on Actions and Events. Oxford: Clarendon Press, 1980. p. 83-102.

FINK, E. “Oasis of Happiness: Thoughts Toward an Ontology of Play". In: MOORE, I.A.; TURNER, C. (trad.), Play as Symbol of the World and Other Writings. Bloomington, IN: Indiana University Press, 2015. pp. 13-31.

HUIZINGA, J. Homo Ludens. São Paulo: Perspectiva, 2000. 
JUUL, J. Half-Real: Video Games Between Real Rules and Fictional Worlds. Cambridge, MA: MIT Press. 2005.

KANIA, M.M. Perspectives of the Avatar: Sketching the Existential Aesthetics of Digital Games. Wroclaw: University of Lower Silesia Press. 2017.

KLEVJER, R. "Enter the Avatar: The Phenomenology of Prosthetic Telepresence in Computer Games". In: SAGENG, J.R., et al. (eds.), The Philosophy of Computer Games, Philosophy of Engineering and Technology 7, p.17-38. 2012.

KWASTEK, K. Aesthetics of Interaction in Digital Art. Cambridge, MA: MIT Press. 2013.

LANKOSKI, P. "Player Character Engagement in Computer Games". Games and Culture, n. 6, p. 291-391, 2011.

MATEAS, M.; STERN, A. "Interaction and Narrative" In: The Game Design Reader: A Rules of Play Anthology. SALEN, K.; ZIMMERMAN, E. (eds.). Boston, MA: MIT Press, 2005. p. 642669.

MERLEAU-PONTY, M. Phenomenology of Perception. London: Routledge, 2002.

MERLEAU-PONTY, M. The Visible and the Invisible, Evanston, IL: Northwestern University Press, 1968.

MURRAY, J.H. Hamlet on the Holodeck. Cambridge, MA: MIT Press, 1997.

PROPRIOCEPTIVA. In: MICHAELIS Dicionário Brasileiro da Língua Portuguesa. 2018.

RICOEUR, P. Time and Narrative, vol. 1. Chicago, IL: Chicago University Press, 1984.

RICOEUR, P. Oneself as Another. Chicago, IL: University of Chicago Press, 1992.

RICOEUR, P. 0 Si-mesmo como outro. São Paulo: Martins Fontes, 2014.

SALEN, K.; ZIMMERMANN, E. Regras do Jogo: fundamentos do design de jogos. São Paulo: Blucher, 2012.

SCHELER, MAX. Formalism in Ethics and Non-Formal Ethics of Values. Trad: Manfred S. Frings and Roger L. Funk. Evanston, IL: Northwestern University Press. 1973.

STRAWSON, P.F. Individuals: An Essay in Descriptive Metaphysics. London: Methuen, 1959.

WARDRIP-FRUIN, N. et al. Agency Reconsidered. In: DIGRA, 2009, Londres. Proceedings [...]. Londres: 2009.

VON WRIGHT, G.H. Explanation and Understanding. Ithaca, NY: Cornell University Press, 1971. 


\title{
Referência Ludográfica
}

THIEF: THE DARK PROJECT. Looking Glass Studios, PC, 1998.

\section{Action as the basis for an aesthetics of ludic subjectivity}

\begin{abstract}
The relevance of recognizing the sense of agency as being fundamental to the player's experience of engaging with the gameworld has often been pointed out. In this paper, I wish to examine the idea of action being constitutive of the player's ingame self, that is, the sense of who she is in relation to the gameworld. To this end, the observation concentrates on games in which the player is embodied in the gameworld in the form of a single playable figure, establishing an embodied ludic subjectposition from which the player acts out a ludic subjectivity. In order to ground the analysis into the enactment of ludic subjectivity, the first step focuses on the conceptuality of the relation between action and the subject. The identification of a conceptual schema within which to tackle this question paved the way to approaches to action both within the tradition of analytic philosophy and within continental philosophy. Following this path, the paper makes the case that the experiential structure of digital gameplay, organized around the interplay between a perspective internal to the gameworld - that of the ludic subject-position - and a distanced, external perspective, allows for the player's enactment of ludic subjectivity to itself be brought into view, structuring an aesthetics of ludic subjectivity that is inseparable from - and, indeed, consequent to, the player's taking-action in the gameworld.
\end{abstract}

\section{Keywords}

Action. Aesthetics. Ludic Subjectivity. Thief: The Dark Project. 